\title{
A Semi-Coupled Model for Morphological Flow Simulation in River Bend
}

\author{
K. Bora and H. M. Kalita ${ }^{\dagger}$ \\ Department. of Civil Engineering., National Institite of Technology, Meghalaya, Shillong,793003, India \\ †Corresponding Author Email: hriday@nitm.ac.in
}

(Received August 9, 2019; accepted February 8, 2020)

\begin{abstract}
This paper presents a new efficient and robust numerical model for morphological flow simulation in river bends. The hydrodynamic model is developed by solving the two dimensional (2D) shallow water equations using a total variation diminishing (TVD) MacCormack predictor corrector scheme. The present TVD method is very simple and provides accurate results free from numerical oscillations near sharp gradient. The effective stresses are modeled by using a constant eddy viscosity model. The sediment transport model solves the Exner equation using a simple forward time and central space (FTCS) finite difference algorithm. The sediment transport model incorporates the helical flow and the transverse bed slope effects on the sediment direction computation. These models are coupled using the semicoupled approach. The present semicoupled model is used to replicate two popular experimental test cases of both tight and loose channel bends. The obtained results in terms of bed level variation reveal that the model can accurately simulate several features of the bed changes such as oscillations of the transverse bed profile with the formation of point bars and pools along the banks. The values obtained for three widely used statistical parameters show the applicability of the present model for this type of complex scenarios.
\end{abstract}

Keywords: Shallow water equations; Exner equation; TVD MacCormack scheme; FTCS scheme; Semicoupled model; Sediment transport model.

\section{NOMENCLATURE}

$C \quad$ chezy coefficient

$C_{r} \quad$ local courant number

$D_{50} \quad$ median grain size

$f_{s} \quad$ sediment shape factor

$g$ gravitational acceleration

$h \quad$ depth of flow

$J \quad$ jacobian determinant

$K \quad$ von karman constant

$L_{i, j}^{k} \quad$ spatial and temporal grid level

$l_{\xi} \quad$ finite difference operators in $\xi$ direction

$l_{\eta} \quad$ finite difference operators in $\eta$ direction

$n \quad$ mannings roughness parameter

$n n \quad$ number of grids

$q_{s} \quad$ total bed load discharge per unit width

$q_{s x}$ bed load discharge/unit width in $\mathrm{x}$ direction

$q_{s y}$ bed load discharge/unit width in $\mathrm{y}$ direction

$r$

\begin{tabular}{|c|c|}
\hline$r_{c}$ & radius of curvature of streamlines \\
\hline$S$ & specific gravity of sediment \\
\hline$u$ & velocity components in $\mathrm{x}$ direction \\
\hline$v$ & velocity components in y direction \\
\hline$Z$ & bed elevation \\
\hline Zexp & experimental non dimensional relative bed \\
\hline & variation znum experimental non \\
\hline & dimensional relative bed variation \\
\hline$\alpha$ & angle of sediment transport direction \\
\hline$\alpha_{t}$ & empirical coefficient \\
\hline$v_{t}$ & eddy viscosity \\
\hline$\lambda$ & porosity of the bed material \\
\hline$\xi$ & computational domain in $\mathrm{x}$ direction \\
\hline$\eta$ & computational domain in y direction \\
\hline$\theta$ & shields parameter \\
\hline$\delta$ & direction of bed shear stress \\
\hline$\varphi$ & cylindrical coordinates of bed shear stress \\
\hline
\end{tabular}

(or helical flow), turbulence, river bed form change, river plan form change, etc. In a river bend, scour generally occurs along the outer bank while the deposition occurs along the inner one, due to the
Flow in a river bend is a complex phenomenon as it involves several processes such as, secondary flow 
difference of centrifugal forces between the upper and the lower layer of flow (Kassem and Chaudhry 2002). Erosion can undermine or destroy the river training structures, while deposition may obstruct water intakes or the navigations canals (Vasquez 2005).

Modelling can provide some prior idea regarding scouring, deposition, etc., which is of significant practical concern. Models may be classified into analytical (or theoretical), experimental or numerical, based on the approach used. El-Khudairy (1970) developed one of the pioneer analytical models for determining the steady state transverse bed profile in a channel bend. After that several analytical models (Engelund 1974; Kikkawa, Ikeda, and Kitagawa 1976; Zimmerman and Kennedy 1978; Odgaard 1981; Parker, Sawai, and Ikeda 1982; Seminara, Zolezzi, Tubino, and Zardi 2001) are reported in the literature for bend flow simulation. These models however, are applicable only for simple bends due to several assumptions associated with it. Moreover, they are also restricted to steady analysis due to the same reason. Experimental analysis can overcome these issues to a great extent. Hooke (1974) did one of the earliest experimental studies in the University of Uppsala, Sweden. He observed that the region of maximum bed shear stress and maximum sediment discharge is on the point bar in the upstream of the bend. It crosses the channel centerline in the middle part of the bend and follows the concave bank to the next point bar downstream. Sutmuller and Glerum (1980) conducted experiments in $180^{\circ}$ channel bend and found out the point bar height and pool depth. Struiksma (1983) did similar experiments for $140^{\circ}$ channel bend considering three different discharge values. For each discharge value, he found out the velocity and bed profiles at different cross sections throughout the channel length. Garcia and Ni ño (1993) tried to determine the height, wavelength, and celerity of alternate bars in an experimental channel bend. Rahman et al. (1996) performed experimental studies to analyze the morphological changes of meandering channel with special attention to bank erosion. Roca et al. (2007) developed physical models for simulating the bend scour and its prevention by outer bank footing. Abad and Garcia (2009) conducted experimental studies to examine the effect of bend orientation on river bed morphodynamics. Uddin and Rahman (2012) conducted an experimental study for observing the flow and scour pattern in a bend of River Yamuna, Bangladesh. In a more recent study, Lee and Dang (2018) did experimental studies to determine the degradation depth in a $90^{\circ}$ channel bend.

Even though experimental model can easily be used to analyze the scouring, deposition and all related phenomenon in a channel bend, it has some inherent limitations. Some of such are high investment and maintenance cost, scale issues, repetitive approach, etc. With the advent of computer powers in last few decades, researchers have started giving effort for numerical simulation of morphological processes in channel bend. The morphological process in a channel bend is truly a three dimensional (3D) process in nature and therefore it is advantageous to use 3D models in this regard. This has leads to development of many 3D models for this purpose. Wang and Adeff (1986) developed a 3D model for water flow and sediment transport using finite element method. Demuren (1991) proposed a 3D numerical model for morphological simulation in channel bend employing k- $\varepsilon$ turbulence model. Wu et al. (2000) presented a 3D numerical model for hydrodynamic and morphological flow simulation of a channel bend. They solved the Reynolds-averaged Navier-Stokes equations using finite volume method for this purpose. Olesen (1985) developed 3D numerical model for computing the meander planform, meander wave-length and downstream meander migration in a meandering channel. Khosronejad et al. (2007) developed a 3D model for numerical simulation of flow and sediment transport in channel bend and observed that $\mathrm{k}-\omega$ model performs better than $\mathrm{k}-\varepsilon$ model. Ramamurthy et al. (2012) proposed a 3D model for morphological flow simulation in sharp channel bend and observed that Volume of Fluid approach is excellent in this regard. Khosronejad et al. (2015) developed a 3D numerical model in curvilinear coordinates for studying the bed elevation changes in a channel bend equipped with in-stream rock structures. Khosronejad et al. (2018) extended the same model to determine the optimal location of rock-vane in channel bends.

Despite the fact that $3 \mathrm{D}$ models are superior for morphological flow simulation in channel bends, the computational cost of 3D models is very high and often prohibitive for engineering analysis and design studies (Begnudelli, Valiani, and Sanders 2010). Under certain considerations and limitations, it is feasible to use 2D depth averaged models to conquer this problem, specifically for certain engineering applications (Lane and Ferguson 2005). This has motivated many researchers to develop 2D numerical models for flow and sediment transport in channel bends. Flokstra and Koch (1981) proposed one of the pioneer 2D numerical models for flow and sediment transport in channel bends. They applied their model to simulate the bed elevation changes in a $180^{\circ}$ channel bend and found that their model could reproduce the point bar near the the inner bank and also the pool near the outer bank. However, their model could not replicate the asymmetry of the bed topography. In addition, their model is applicable only for steady flow. Struiksma et al. (1985) proposed a 2D steady numerical model for morpholgical simulation in channel bends. However, their model can only be applied for channel geometry which can be represented as a series of circular bends of constant width. Shimizu and Itakura (1989) developed another steady 2D morphological model in cylindrical coordinate sys-tem. However, it is valid only for definite geometry. In order to overcome this steady flow and specific geometry issues, Kassem and Chaudhry (2002), for the first time presented a 2D boundary fitted numerical model for simulation of bed deformation in channel bends. The problem with their model is that it is based on a numerical model, which is subjected to artificial 
viscosity for stability. The model is very much sensitive to the artificial viscosity coefficient. Vasquez et al. (2008) developed a 2D depth averaged model for simulating the scour and the depsotion in a meandering channel. For this purpose, they solved the 2D shallow water equations using unstructured triangular elements. Abad et al. (2008) developed a numerical model for morphological flow simulation in channel bends using curvilinear coordinates and promising results are obtained. However, it is again restricted to steady flow and could not locate the point bar downstream of the curve when applied in a channel bend. Begnudelli et al. (2010) proposed another 2D model in the same regard by using Godunov-type finite volume method. Their model also could not replicate the point bar and the pool downstream of the curve, when applied to Sutmuller and Glerum (1980) test channel.

The present work proposes a simple but effective numerical model for 2D simulation of hydrodynamic and morphological flow simulation in river bend. For the hydrodynamic portion, it solves the unsteady shallow water equations in a boundary fitted coordinate system using a TVD based MacCormack predictor corrector scheme. Therefore, it may be applied to complex river planform as well as for unsteady cases. The advantage of present TVD version is that it does not require any calculation of eigen values and eigen vectors. For the morphological modelling, the Exner sediment continuity equation is solved using a simple finite difference scheme. Finally, both the models are coupled using the simple semicoupled manner.

\section{NUMERICAL MODEL}

\subsection{Hydrodynamic Equations and Numerical Solution}

Assuming a hydrostatic pressure distribution, the 2D shallow water equations can be derived by vertically integrating the Reynolds-Averaged Navier Stokes equations (Chaudhry 2007). Neglecting wind shear, ignoring Coriolis acceleration and for small bottom slope, these hydrodynamic governing equations can be written as (Alauddin and Tsujimoto 2012)

$$
\begin{aligned}
& \frac{\partial S}{\partial t}+\frac{\partial(h u)}{\partial x}+\frac{\partial(h v)}{\partial y}=0 \\
& \frac{\partial(h u)}{\partial t}+\frac{\partial\left(h u^{2}\right)}{\partial x}+\frac{\partial(h u v)}{\partial y}= \\
& -h g \frac{\partial S}{\partial x}-\frac{g n^{2} u \sqrt{u^{2}+v^{2}}}{h^{\frac{1}{3}}}+\frac{\partial}{\partial x}\left[v_{t} \frac{\partial(h u)}{\partial x}\right]+\frac{\partial}{\partial y}\left[v_{t} \frac{\partial(h u)}{\partial y}\right] \\
& \frac{\partial(h v)}{\partial t}+\frac{\partial(h u v)}{\partial x}+\frac{\partial\left(h v^{2}\right)}{\partial y}= \\
& -h g \frac{\partial S}{\partial y}-\frac{g n^{2} v \sqrt{u^{2}+v^{2}}}{h^{\frac{1}{3}}}+\frac{\partial}{\partial x}\left[v_{t} \frac{\partial(h v)}{\partial x}\right]+\frac{\partial}{\partial y}\left[v_{t} \frac{\partial(h v)}{\partial y}\right]
\end{aligned}
$$

where $\mathrm{S}$ is elevation of water surface, $\mathrm{h}$ is depth of flow, $\mathrm{u}, \mathrm{v}$ are velocity components in $\mathrm{x}$ and $\mathrm{y}$ directions, respectively, $\mathrm{g}$ is gravitational aceleration, and $\mathrm{n}$ is Mannings roughness parameter. In the momentum equations (Eqs. 2 and 3), $v_{t}$ is the eddy viscocity due to turbulence and is calculated here using the depth averaged parabolic eddy viscosity model (Wu 2007) given as

$$
v_{t}=\alpha_{t} h \sqrt{\frac{g n^{2}}{h^{\frac{1}{3}}}\left(u^{2}+v^{2}\right)}
$$

where $\alpha_{\mathrm{t}}$ is an empirical coefficient between 0.3 and 1.0 (Elder 1959). This value is kept as 0.7 throughout the study.

The planform of natural rivers is mostly irregualr in shape and application of the above governing equations in that case becomes very difficult. In order to overcome this issue, the equations are transformed from the physical domain $(\mathrm{x}, \mathrm{y})$ to a computational domain $(\xi, \eta)$ and given as (Anderson et al. 1984)

$$
\frac{\partial(J S)}{\partial t}+\frac{\partial}{\partial \xi}\left(h u y_{\eta}-h v x_{\eta}\right)+\frac{\partial}{\partial \eta}\left(h v x_{\xi}-h u y_{\xi}\right)=0
$$

$$
\begin{aligned}
& \frac{\partial}{\partial t}(J h u)+\frac{\partial}{\partial \xi}\left(h u^{2} y_{\eta}-h u v x_{\eta}\right)+\frac{\partial}{\partial \eta}\left(h u v x_{\xi}-h u^{2} y_{\xi}\right) \\
& =-g h y_{\eta} \frac{\partial S}{\partial \xi}+g h y_{\xi} \frac{\partial S}{\partial \eta}-J \frac{g n^{2} u \sqrt{u^{2}+v^{2}}}{h^{\frac{1}{3}}}+D 1+D 2
\end{aligned}
$$

$$
\begin{aligned}
& \frac{\partial}{\partial t}(J h v)+\frac{\partial}{\partial \xi}\left(h u v y_{\eta}-h v^{2} x_{\eta}\right)+\frac{\partial}{\partial \eta}\left(h v^{2} x_{\xi}-h u v y_{\xi}\right) \\
& =g h x_{\eta} \frac{\partial S}{\partial \xi}-g h x_{\xi} \frac{\partial S}{\partial \eta}-J \frac{g n^{2} u \sqrt{u^{2}+v^{2}}}{h^{\frac{1}{3}}}+D 3+D 4
\end{aligned}
$$

where the diffusive terms D1, D2, D3 and D4 are given as

$$
\begin{aligned}
& D 1=v_{t}\left\{\frac{1}{J} y_{\eta}^{2} \frac{\partial^{2}}{\partial \xi^{2}}(h u)+\frac{1}{J} x_{\eta}^{2} \frac{\partial^{2}}{\partial \xi^{2}}(h u)\right. \\
& \left.-\frac{1}{J} y_{\eta} y_{\xi} \frac{\partial^{2}}{\partial \xi \partial \eta}(h u)-\frac{1}{J} x_{\eta} x_{\xi} \frac{\partial^{2}}{\partial \xi \partial \eta}(h u)\right\} \\
& D 2=v_{t}\left\{\frac{1}{J} y_{\xi}^{2} \frac{\partial^{2}}{\partial \eta^{2}}(h u)+\frac{1}{J} x_{\xi}^{2} \frac{\partial^{2}}{\partial \eta^{2}}(h u)\right. \\
& \left.-\frac{1}{J} y_{\xi} y_{\eta} \frac{\partial^{2}}{\partial \eta \partial \xi}(h u)-\frac{1}{J} x_{\xi} x_{\eta} \frac{\partial^{2}}{\partial \eta \partial \xi}(h u)\right\} \\
& D 3=v_{t}\left\{\frac{1}{J} y_{\eta}^{2} \frac{\partial^{2}}{\partial \xi^{2}}(h v)+\frac{1}{J} x_{\eta}^{2} \frac{\partial^{2}}{\partial \xi^{2}}(h v)\right. \\
& \left.-\frac{1}{J} y_{\eta} y_{\xi} \frac{\partial^{2}}{\partial \xi \partial \eta}(h v)-\frac{1}{J} x_{\eta} x_{\xi} \frac{\partial^{2}}{\partial \xi \partial \eta}(h v)\right\}
\end{aligned}
$$




$$
\begin{aligned}
& D 4=v_{t}\left\{\frac{1}{J} y_{\xi}^{2} \frac{\partial^{2}}{\partial \eta^{2}}(h v)+\frac{1}{J} x_{\xi}^{2} \frac{\partial^{2}}{\partial \eta^{2}}(h v)\right. \\
& \left.-\frac{1}{J} y_{\xi} y_{\eta} \frac{\partial^{2}}{\partial \eta \partial \xi}(h v)-\frac{1}{J} x_{\xi} x_{\eta} \frac{\partial^{2}}{\partial \eta \partial \xi}(h v)\right\}
\end{aligned}
$$

In Eqs. 5-11, $\mathrm{x}_{\xi}, \mathrm{y}_{\xi}, \mathrm{x}_{\eta}, \mathrm{y}_{\eta}$ are some coefficients obtained due to grid transformation and are determined here using central difference approximations. $\mathrm{J}$ is the Jacobian determinant of grid transformation and given as

$J=x_{\xi} y_{\eta}-x_{\eta} y_{\xi}$

In matrix form, Eqs. 5-7 can be written as

$\frac{\partial L}{\partial t}+\frac{\partial M}{\partial \xi}+\frac{\partial N}{\partial \eta}=R$

where,

$L=\left\{\begin{array}{l}J S \\ J h u \\ J h v\end{array}\right\}, M=\left\{\begin{array}{c}h u y_{\eta}-h v x_{\eta} \\ h u^{2} y_{\eta}-h u v x_{\eta} \\ h u v y_{\eta}-h v^{2} x_{\eta}\end{array}\right\}$,
$N=\left\{\begin{array}{c}h v x_{\xi}-h u y_{\xi} \\ h u v x_{\xi}-h u^{2} y_{\xi} \\ h v^{2} x_{\xi}-h u v y_{\xi}\end{array}\right\}$ and
$R=\left\{\begin{array}{c}-g h y_{\eta} \frac{\partial S}{\partial \xi}+g h y_{\xi} \frac{\partial S}{\partial \eta}-J \frac{g n^{2} u \sqrt{u^{2}+v^{2}}}{h^{\frac{1}{3}}} \\ +D 1+D 2 \\ g h x_{\eta} \frac{\partial S}{\partial \xi}-g h x_{\xi} \frac{\partial S}{\partial \eta}-J \frac{g n^{2} v \sqrt{u^{2}+v^{2}}}{h^{\frac{1}{3}}} \\ +D 3+D 4\end{array}\right\}$

The above hydrodynamic equations representing the 2D unsteady open channel flow are a set of mixed hyperbolic partial differential equations. Therefore, it is very difficult to solve them analytically and mostly they are targeted with numerical approaches. MacCormack predictor corrector scheme (MacCormack 2003) is one of the excellent and widely used numerical techniques in this regard. Many researchers (Liang, Özgen, Hinkelmann, Xiao, and Chen 2015; Bellos and Tsakiris 2015; Bellos, Kourtis, Moreno-Rodenas, and Tsihrintzis 2017) have applied this technique for the shallow water equations in diverse situations. This second order accurate method is composed of two steps namely predictor and corrector steps. Even though the method is very simple and efficient, it faces the dispersion error (Anderson, Tannehill, and Pletcher 2016) when applied to hyperbolic equations. A TVD approach is used here to remove the dispersion error. The TVD method proposed by Davis (1984) is utilized here due to its independency on characteristic transformation (Liang, Lin, and
Falconer 2007).

The 2D problem is splitted into a sequence of two one dimensional (1D) problems and is solved at each time step. Using the operator splitting given by Strang (1968), Eq. 13 maybe splitted to

$$
\begin{aligned}
& \frac{\partial L}{\partial t}+\frac{\partial M}{\partial \xi}=P \\
& \frac{\partial L}{\partial t}+\frac{\partial N}{\partial \eta}=Q
\end{aligned}
$$

where,

$$
P=\left\{\begin{array}{c}
0 \\
-g h y_{\eta} \frac{\partial S}{\partial \xi}-J \frac{g n^{2} u \sqrt{u^{2}+v^{2}}}{h^{\frac{1}{3}}}+D 1 \\
g h x_{\eta} \frac{\partial S}{\partial \xi}+D 3 \\
g h y_{\xi} \frac{\partial S}{\partial \eta}+D^{2} \\
-g h x_{\eta} \frac{\partial S}{\partial \eta}-J \frac{g n^{2} u \sqrt{u^{2}+v^{2}}}{h^{\frac{1}{3}}}+D 4
\end{array}\right\}
$$

The finite difference sequence followed for the 1D problems in Eqs. 15 -16 are given as

$$
L_{i, j}^{k+1}=l_{\xi} l_{\eta} l_{\eta} l_{\xi} L_{i, j}^{k}
$$

where $1 \xi$ and $l_{\eta}$ are the finite difference operators along $\xi$ and $\eta$ directions, respectively. The subscript and superscript of $\mathrm{L}$ represents the spatial and temporal grid levels, respectively. It can be easily seen from Eq. 17 that values of the primitive flow variables are computed at next step by employing four consecutive sweeps. Equation 15 is solved first in $\xi$ direction using the initial values of the flow parameters (sweep 1). After that Eq. 16 is solved in $\eta$ direction using the latest updated values (sweep 2). After that Eq. 16 is again solved in $\eta$ direction using the latest updated values (sweep 3). Finally, Eq. 15 is solved in $\xi$ direction using the latest updated values, to get the final values at next time step (sweep 4). It may be mentioned here that sweep 1 and sweep 4 are exactly same except that the initial values are different. Similarly, sweep 2 and sweep 3 are also similar to each other except the initial values. Only sweep 1 is discussed here in detail to save the space. Sweep 2 can easily be implementated by considering finite difference approximation in $\eta$ direction (using index j). The first sweep of Eq. 17 in $\xi$ direction can be written as

$$
L_{i}^{p}=L_{i}^{k}-\frac{\Delta t}{\Delta \xi}\left(M_{i}^{k}-M_{i-1}^{k}\right)+\Delta t P_{i}^{k}
$$




$$
\begin{aligned}
& L_{i}^{c}=L_{i}^{k}-\frac{\Delta t}{\Delta \xi}\left(M_{i+1}^{p}-M_{i}^{p}\right)+\Delta t P_{i}^{p} \\
& L_{i, j}^{k+1}=\frac{1}{2}\left(L_{i}^{p}+L_{i}^{c}\right) L_{i}^{k}+T V D_{i}
\end{aligned}
$$

Where,

$$
\begin{aligned}
& T V D_{i}=\left\{G\left(r_{i}^{+}\right)+G\left(r_{i+1}^{-}\right)\right\} \Delta L_{i+\frac{1}{2}}^{k} \\
& -\left\{G\left(r_{i-1}^{+}\right)+G\left(r_{i}^{-}\right)\right\} \Delta L_{i-\frac{1}{2}}^{k}
\end{aligned}
$$

Equation 21 represents the TVD step added in $\xi$ direction. $\Delta \xi$ and $\Delta \mathrm{t}$ are the grid spacings in $\xi$ and time directions, respectively. Superscripts $\mathrm{p}$ and $\mathrm{c}$ stands for predicted and corrected values, respectively. Subscript $i$ is the index in $\xi$ direction.

In Eq. 21,

$$
\begin{aligned}
& \Delta L_{i+\frac{1}{2}}^{k}=L_{i+1}^{k}-L_{i}^{k} \\
& \Delta L_{i-\frac{1}{2}}^{k}=L_{i}^{k}-L_{i-1}^{k} \\
& r_{i}^{+}=\frac{\Delta S_{i-\frac{1}{2}}^{k} \cdot \Delta S_{i+\frac{1}{2}}^{k}+\Delta(h u)_{i-\frac{1}{2}}^{k} \cdot \Delta(h u)_{i+\frac{1}{2}}^{k}++\Delta(h v)_{i-\frac{1}{2}}^{k} \cdot \Delta(h v)_{i+\frac{1}{2}}^{k}}{\Delta S_{i+\frac{1}{2}}^{k} \cdot \Delta S_{i+\frac{1}{2}}^{k}+\Delta(h u)_{i+\frac{1}{2}}^{k} \cdot \Delta(h u)_{i+\frac{1}{2}}^{k}++\Delta(h v)_{i+\frac{1}{2}}^{k} \cdot \Delta(h v)_{i+\frac{1}{2}}^{k}} \\
& r_{i}^{-}=\frac{\Delta S_{i-\frac{1}{2}}^{k} \cdot \Delta S_{i+\frac{1}{2}}^{k}+\Delta(h u)_{i-\frac{1}{2}}^{k} \cdot \Delta(h u)_{i+\frac{1}{2}}^{k}++\Delta(h v)_{i-\frac{1}{2}}^{k} \cdot \Delta(h v)_{i+\frac{1}{2}}^{k}}{\Delta S_{i-\frac{1}{2}}^{k} \cdot \Delta S_{i-\frac{1}{2}}^{k}+\Delta(h u)_{i-\frac{1}{2}}^{k} \cdot \Delta(h u)_{i-\frac{1}{2}}^{k}++\Delta(h v)_{i-\frac{1}{2}}^{k} \cdot \Delta(h v)_{i-\frac{1}{2}}^{k}}
\end{aligned}
$$

The expression for $\mathrm{G}()$ in Eq. 21 is

$$
G(f)=0.5 \times c \times[1-\varphi(f)]
$$

where the flux limiter function $\varphi(f)$ is given by

$$
\varphi(f)=\max \{0, \min (2 f, 1)\}
$$

and the value of the variable $\mathrm{c}$ is given as

$$
c=\left\{\begin{array}{c}
C r \times(1-C r), \text { if } \quad \mathrm{Cr} \leq 0.5 \\
0.25, \text { if } \quad \mathrm{Cr}>0.5
\end{array}\right.
$$

Where $\mathrm{Cr}$ is the local courant number given as

$$
C r=\frac{(|u|+\sqrt{g h}) \Delta t}{\Delta x}
$$

\subsection{Sediment Transport Equation and Numerical Solution}

Neglecting grain sorting and considering only bed load transport, the 2D sediment continuity equation can be written as (Struiksma et al. 1985)

$$
\frac{\partial Z}{\partial t}+\frac{1}{1-\lambda}\left(\frac{\partial q_{s x}}{\partial x}+\frac{\partial q_{s y}}{\partial y}\right)=0
$$

Where $\mathrm{Z}$ is the bed elevation, $\mathrm{q}_{\mathrm{sx}}$ and $\mathrm{q}_{\mathrm{sy}}$ are components of bed load discharges per unit width in $\mathrm{x}$ and $\mathrm{y}$ directions, respectively and $\lambda$ is the porosity of the bed material (a default value of 0.4 is considered here). If $\alpha$ is the angle of sediment transport direction, the components of bed load transport can be calculated from

$q_{s x}=q_{s} \cos (\alpha), q_{s y}=q_{s} \sin (\alpha)$

in which $\mathrm{q}_{\mathrm{s}}$ is the total bed load discharge per unit width and is calculated here using the formula given by Engelund (1974) as

$q_{s}=0.05 \sqrt{\left((S-1) g D_{50}^{3}\right)} \frac{C^{2}}{g} \theta^{\frac{5}{2}}$

where $S$ is specific gravity of sediment, $D_{50}$ is median grain size, $\mathrm{C}$ is Chezy coefficient and $\theta$ is Shields parameter. The expression of Shields parameter is given as

$$
\theta=\frac{u^{2}+v^{2}}{C^{2}(S-1) D_{50}}
$$

Whenever flow takes place in channel bend, a secondary (or helical) flow is generated due to centrifugal acceleration. This leads to movement of bed sediment from the outer bank to the inner bank. Therefore, the bed changes in a channel bend is directly related to the helical intensity. This helical flow causes the direction of bed shear stress $(\delta)$ to deviate from the mean flow velocity. Employing a secondary flow correction (Struiksma, Olesen, Flokstra, and De Vriend 1985), $\delta$ can be found out from

$$
\delta=\arctan \left(\frac{u}{v}\right)-\arctan \left(\frac{A h}{r_{c}}\right)
$$

where $r_{c}$ is the radius of curvature of streamlines and is defined as

$$
r_{c}=\frac{\left(u^{2}+v^{2}\right)^{\frac{3}{2}}}{-u v \frac{\partial u}{\partial x}-v^{2} \frac{\partial u}{\partial y}+u^{2} \frac{\partial v}{\partial x}+u v \frac{\partial v}{\partial y}}
$$

Parameter A in Eq. 33 is considered here to vary with cases and is given as

$A=\frac{2}{K^{2}}\left(1-\frac{\sqrt{g}}{K C}\right)$

in which $\mathrm{K}$ is Von Karman constant $(=0.4)$.

Whenever there is some lateral slope in the channel bed, the sediment transport direction deviates from the bed shear stress $(\delta)$ due to gravity force on the sediment particle. The sediment transport direction $(\alpha)$ is then calculated from the below equation (Flokstra and Koch 1981; Struiksma, Olesen, Flokstra, and De Vriend 1985): 


$$
\tan \alpha=\frac{\sin \delta-\frac{1}{f_{s} \theta} \frac{\partial Z}{\partial y}}{\cos \delta-\frac{1}{f_{s} \theta} \frac{\partial Z}{\partial x}}
$$

where $\mathrm{f}_{\mathrm{s}}$ is the sediment shape factor, $\frac{\partial Z}{\partial x}$ and $\frac{\partial Z}{\partial y}$ are the bed slopes in $\mathrm{x}$ and $\mathrm{y}$ directions, respectively.

In an alluvial channel bend starting from a flat bed, sediment is first transported from the outer bank to the inner bank by the secondary flow. This leads to scouring on the outer bank and deposition on the inner bank. It produces a transverse slope in the direction of flow. As the transverse slope grows, sediment starts to move towards the outer bank due to gravity. Finally, an equilibrium condition is reached between these two effects; when the maximum scouring and deposition is observed in the bend.

In order to make the present model compatible with natural rivers, the sediment continuity equation is also transformed from the physical domain $(\mathrm{x}, \mathrm{y})$ to a computational domain $(\xi, \eta)$ and is given as (Anderson, Tannehill, and Pletcher 2016)

$$
\begin{aligned}
& \frac{\partial}{\partial t}(J Z)+\frac{1}{1-\lambda} \frac{\partial}{\partial \xi}\left(q_{s x} y_{\eta}-q_{s y} x_{\eta}\right) \\
& +\frac{1}{1-\lambda} \frac{\partial}{\partial \eta}\left(q_{s y} x_{\xi}-q_{s x} y_{\xi}\right)=0
\end{aligned}
$$

Equation 37 is solved here using a simple finite difference scheme where the time derivative is approximated by forward difference and the space derivatives are approximated by central difference operators (FTCS scheme). The difference equation after finite difference approximations is given as

$$
\begin{aligned}
& Z_{i, j}^{k+1}=\omega Z_{i, j}^{k}+\frac{1}{4}(1-\omega)\left(Z_{i, j-1}^{k}+Z_{i, j+1}^{k}+Z_{i-1, j}^{k}+Z_{i+1, j}^{k}\right) \\
& -\frac{\Delta t}{2 \Delta \xi(1-\lambda) J_{i, j}^{k}}\left[\left\{\left(q_{s x} y_{\eta}\right)_{i+1, j}^{k}-\left(q_{s y} x_{\eta}\right)_{i+1, j}^{k}\right\}-\left\{\left(q_{s x} y_{\eta}\right)_{i-1, j}^{k}-\left(q_{s y} x_{\eta}\right)_{i-1, j}^{k}\right\}\right] \\
& -\frac{\Delta t}{2 \Delta \eta(1-\lambda) J_{i, j}^{k}}\left[\left\{\left(q_{s x} x_{\xi}\right)_{i, j+1}^{k}-\left(q_{s y} y_{\xi}\right)_{i, j+1}^{k}\right\}-\left\{\left(q_{s x} x_{\xi}\right)_{i, j-1}^{k}-\left(q_{s y} y_{\xi}\right)_{i, j-1}^{k}\right\}\right]
\end{aligned}
$$

where $\omega$ is a diffusion factor and is added here to remove the oscillations during the numerical simulation (Tsakiris and Bellos 2014). A fixed value of 0.99 is used throughout the analysis.

\subsection{Initial and Boundary Conditions}

In order to numerically solve the above governing hydrodynamic and sediment continuity equations, proper initial and boundary conditions are required. Constant discharge values are used as initial condition in the hydrodynamic model. Initial bed elevation is used as initial condition in the morphological model. Initial value of sediment transport is calculated using the flow and sediment properties. Regarding boundary condition, two types of boundary conditions exist here namely, open and closed boundaries. A constant discharge value is used as upstream boundary and the corresponding uniform flow depth for that discharge is used at the down-stream boundary. The solid boundaries are simulated as free slip boundary (Anderson, Tannehill, and Pletcher 2016), i.e. normal velocity component is set to zero and the transverse velocity component is extrapolated from interior domain. Regarding the morphological model, the sediment transport component to solid boundary is set to zero and the tangential component is extrapolated from the interior domain. The bed elevations on the banks are also extrapolated from the interior domain.

\subsection{Semicoupled Approach}

The hydrodynamic and morphological models presented in the earlier section may be linked with two methodologies such as fully coupled and semicoupled approaches. As semicoupled approach has many advantages such as, computationally efficient, ease in incorporating different sediment transport formulas, etc. (Kassem and Chaudhry 2002), the present model uses semicoupled approach in this regard.

Figure 1 shows the flow chart for the model. The model starts with setting the initial values for all the flow variables and sediment properties. The initial bed elevation is also specified. With these data, the hydrodynamic model runs and computes the flow variables $\mathrm{h}, \mathrm{u}$ and $\mathrm{v}$. These flow variables are then used to compute $\mathrm{q}_{\mathrm{sx}}$ and $\mathrm{q}_{\mathrm{sy}}$. The morphological model is then run and subsequently the new bed elevation $(\mathrm{Z})$ is computed. The model then checks one convergence criteria (Convergence-A in the flow chart). According to this convergence, two conditions are to be fulfilled such as (Soulis 2002), (a) the axial velocity component averaged over the flow field between two successive iterations drops below 0.0005 and (b) the axial sediment transport component averaged over the flow field between two successive iterations drops below 0.0005 . If this convergence is not satisfied, the preceding iterations continue. Else, the model updates the bed elevation and accordingly new value of $h$ is computed. These steps will run till Convergence-B is satisfied, if the upstream discharge is constant. The convergence- $\mathrm{B}$ is said to be fulfilled if the bed elevation change averaged over the flow field between two successive iterations drops below 0.00005 . In case of unsteady case, the model runs till the last time step is reached. If this condition of Convergence-B/last time step is reached, the model stops. Else, it again starts from hydrodynamic model.

\section{APPLICATION OF NUMERICAL MODEL}

In order to assess the applicability of the present model, it is applied to two experimental test cases of known bed deformation. Sutmuller and Glerum (1980) experimentally found out the bed deformation in a $180^{\circ}$ channel bend at Laboratory of Fluid Mechanics (LFM) of the Delft University of 
Technology. The experiment T6 of that study is considered here as the first test case. The second case considered here is the experiment (T2) done by Struiksma (1983) at the Delft Hydraulics Laboratory (DHL) in a $140^{\circ}$ channel bend. Figure 2 shows the schematic diagram for both the channel bends. The details of experimental conditions for both the test cases are given in Table 1.

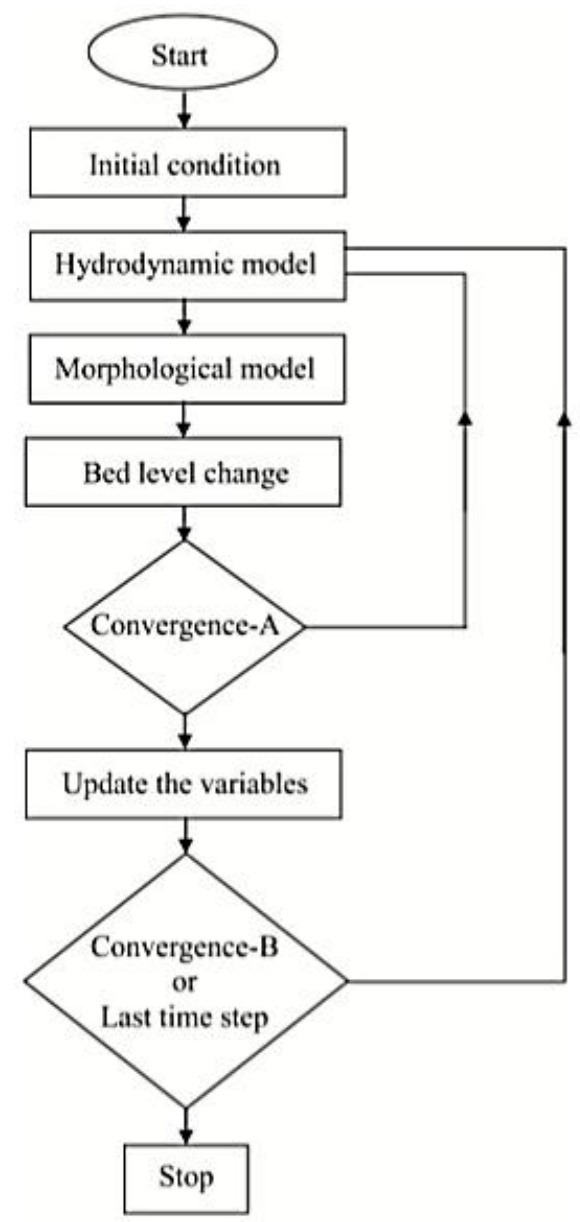

Fig. 1. Flow chart for the present semicoupled model.

Table 1Flow and sediment parameters

\begin{tabular}{|c|c|c|c|}
\hline Parameter & Simbol & LFM & DHL \\
\hline Discharge & $\mathrm{Q}\left(\mathrm{m}^{3} / \mathrm{s}\right)$ & 0.17 & 0.061 \\
\hline Flume width & $\mathrm{B}(\mathrm{m})$ & 1.7 & 1.5 \\
\hline Water depth & $\mathrm{h}(\mathrm{m})$ & 0.20 & 0.10 \\
\hline Flow velocity & $\mathrm{u}(\mathrm{m} / \mathrm{s})$ & 0.50 & 0.41 \\
\hline Water slope & $\mathrm{S}_{0}(\%)$ & 0.18 & 0.203 \\
\hline $\begin{array}{c}\text { Chezy's } \\
\text { co-efficient }\end{array}$ & $\mathrm{Q}\left(m^{\frac{1}{2}} / \mathrm{s}\right)$ & 26.4 & 28.8 \\
\hline $\begin{array}{c}\text { Median grain } \\
\text { diameter }\end{array}$ & $\mathrm{D}_{50}(\mathrm{~mm})$ & 0.78 & 0.45 \\
\hline $\begin{array}{c}\text { Shields } \\
\text { parameter }\end{array}$ & $\theta$ & 0.28 & 0.27 \\
\hline Bend radius & $\mathrm{R}_{\mathrm{c}}(\mathrm{m})$ & 4.25 & 12 \\
\hline Bend length & $\mathrm{L}_{\mathrm{c}}(\mathrm{m})$ & 13.35 & 29.32 \\
\hline
\end{tabular}

\subsection{LFM Test Case}

Sutmuller and Glerum (1980) used uniform sediment in their experiment with standard deviation of $\sigma_{g}=$ 1.15. The specific gravity of the sediment particles is 2.65. In numerical simulation, two straight reaches of length $15 \mathrm{~m}$ each are considered on the upstream and downstream of the bend, to nullify the

boundary effect on the computed result. The whole domain is divided into 1179 finite difference grids. In the straight portions the grid spacings are $\Delta \mathrm{x}=$ $0.3335 \mathrm{~m}$ and $\Delta \mathrm{y}=0.2125 \mathrm{~m}$. The grid spacings in the curved portion are $\Delta \mathrm{r}=0.2125 \mathrm{~m}$ and $\Delta \varphi=4.50$, where $r$ and $\varphi$ are cylindrical coordinates. The value of Mannings coefficient is calculated as 0.028 from the given Chezys coefficient. The value of Courant number is 0.91 . The sediment shape factor is considered as 2 . The upstream flow is considered to be 0.17 cumec and the downstream water depth is considered as $0.2 \mathrm{~m}$. The bed elevation is kept constant at both the upstream and downstream boundaries. The simulation is started from the bed slope as given in Table table 1 and run upto steady state. For this purpose, the time is considered as the iteration number.

Figure 3 shows the relative bed $\left(\Delta Z / H_{0}\right)$ variations with respect to initial water depth computed by the present model along with the experimental result. The same figure also shows the results of previous numerical models of Abad et al. (2008) and Begnudelli et al. (2010). The positive val ues indicate deposition and the negative values indicate scouring of the channel bed. The transverse bed slope generally oscillates along the bend and leads to a large point bar on the inner bank and a deep pool on the outer bank, downstream of the entrance (Vasquez 2005). Around the centre of the bend these phenomenon reduce and again increase around the exit of the bend. This leads to formation of a point bar on the inner bank and a pool on the outer bank, around the exit of the bend. All these deformations are accurately reproduced in the results obtained from the present model (Fig. 3b). In the results reported by Abad et al. (2008)(Fig. 3c), size of the pools on the outer bank is observed to be smaller in compared to experimental one. Further, the height of the point bar on the inner bank is uniform throughout the curve. No point bar is visible around the downstream of the curve. The topographical plot of Begnudelli et al. (2010) (Fig. 3d) does not show any pool around the downstream of the curve. Eventhough their model could correctly reproduce the size of the bigger pool on the outer bank downstream of the entrance, it fails to mimic the bigger point bar at the same location on the inner bank.

Apart from the contour plot of the domain, numerical bed topographies along six cross sections are also compared with the experimental result. Begnudelli et al. (2010) did similar comparisons and reported that their predictions are better than predictions of Abad et al. (2008). The present work therefore compares the result of the current model with the results of Begnudelli et al. (2010). 

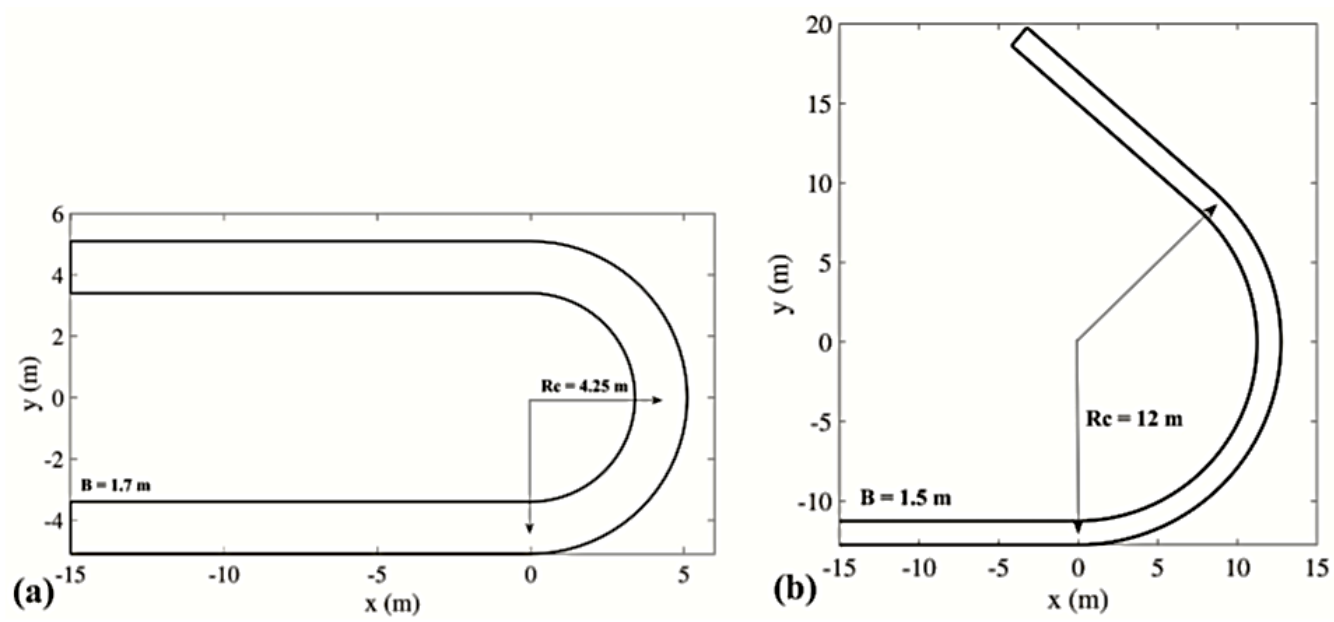

Fig. 2. Schematic view of the test channels: a) LFM flow channel; b) DHL flow channel.

(a)

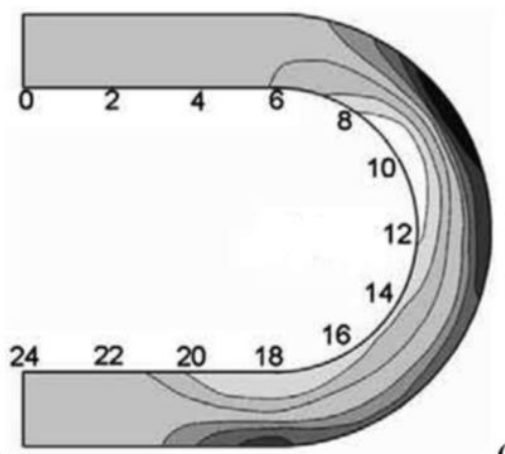

(b)

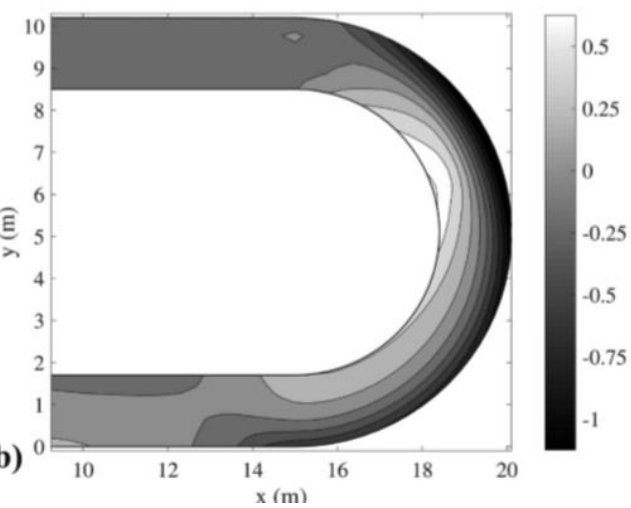

(c)

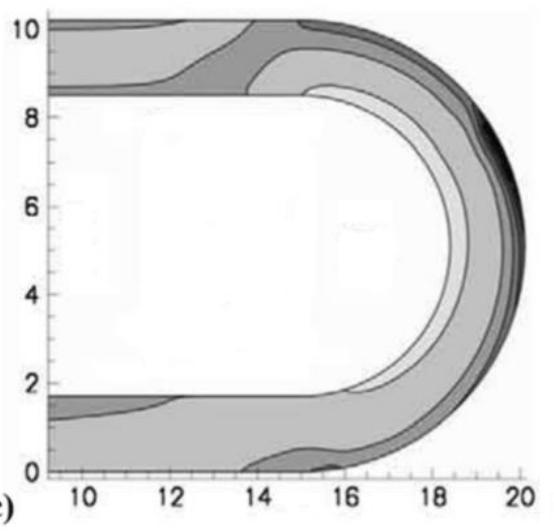

(d)

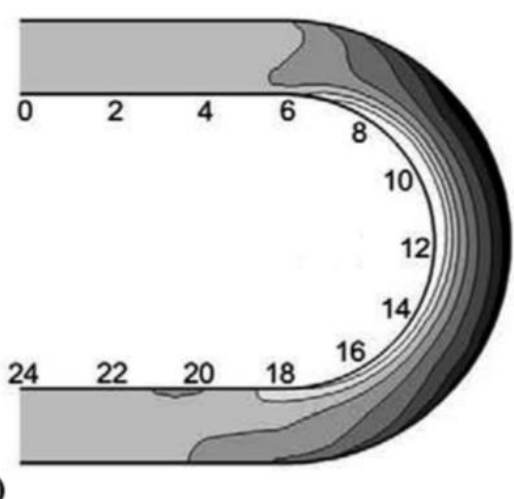

Fig. 3. Relative bed variations with respect to initial water depth $(\Delta \mathrm{Z} / \mathrm{HO})$ for $\mathrm{LFM}$ test case: a) Experiment by Sutmuller and Glerum (1980); b) Prediction by the present model; c) Prediction by Abad et al. (2008); d) Prediction by Begnudelli et al. (2010).

Figure 4 shows the comparison of transverse bed profiles along the cross sections with experimental results and the results obtained by Begnudelli et al.(2010). These figures clearly show that the present model can excellently predict the outer bank scouring, inner bank deposition and also the centreline bed height, for all the sections. The results are also found to be better than the results of Begnudelli et al. (2010). For additional quantitative analysis, two parameters namely, Index of
Agreement (IA)(Willmott 1981) and Nash Indicator (NSE) (Nash and Sutcliffe 1970) are calculated here for all the sections. The expressions for these factors are as given below

$$
I A=1-\frac{\sum_{i=1}^{n n}\left(z_{\exp }-z_{\text {num }}\right)^{2}}{\sum_{i=1}^{n n}\left(\left|z_{\text {num }}-\overline{z_{\exp }}\right|+\left|z_{\exp }-\overline{z_{\exp }}\right|\right)^{2}}
$$



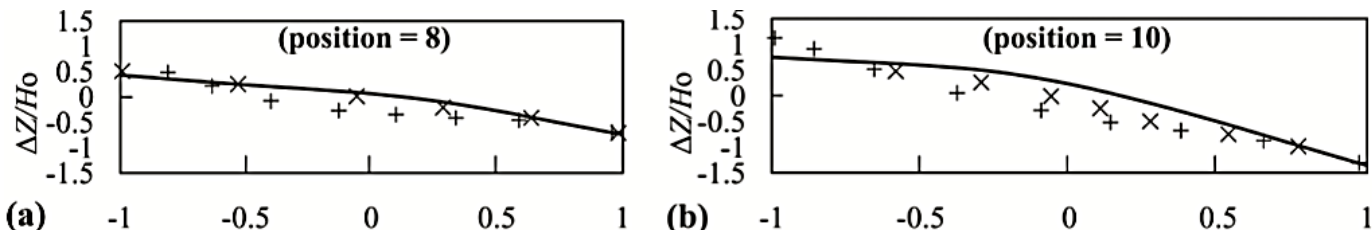

(a)
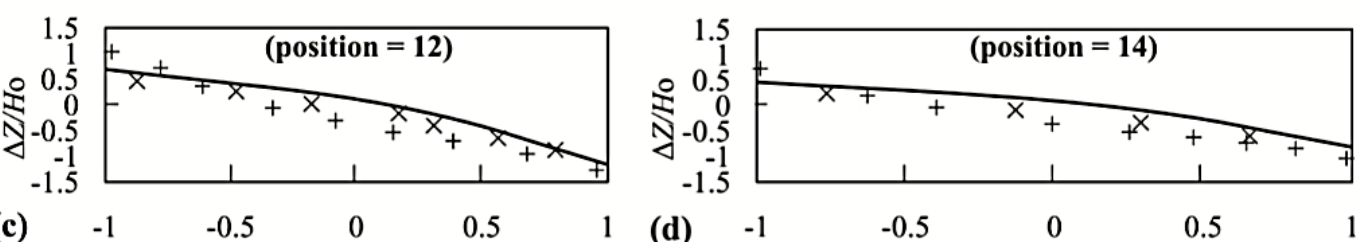

(c)
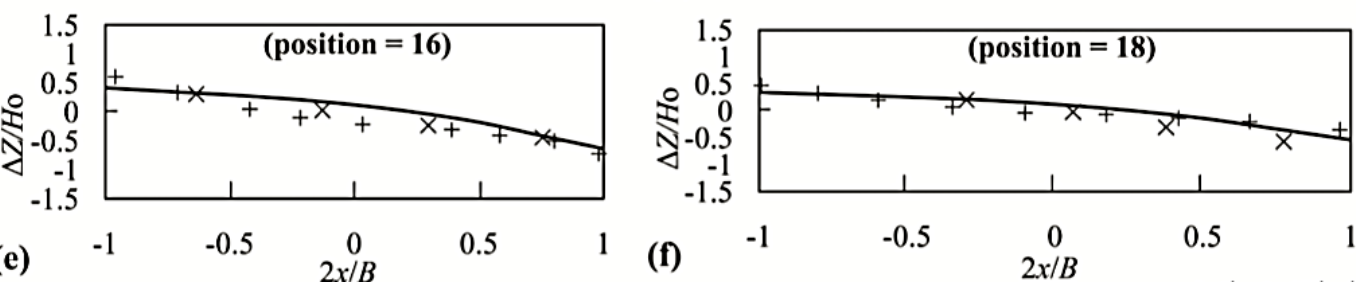

Fig. 4. Comparison by transverse bed profiles for LFM test case: measured (x), predictions by present model (solid line) and predictions by Begnudelli et al. (2010) (+).

$$
N S E=1-\frac{\sum_{i=1}^{n n}\left(z_{\text {num }}-z_{\exp }\right)^{2}}{\sum_{i=1}^{n n}\left(\mid z_{\exp }-\overline{z_{\exp }}\right)^{2}}
$$

Where $\mathrm{nn}$ is the number of grids in the considered cross section, $\mathrm{Z}_{\mathrm{num}}$ is the computed non dimensional relative bed variation, $Z_{\exp }$ is the experimental non dimensional relative bed variation and $z_{\exp }$ is the averaged experimental non dimensional relative bed variation. The numerical values obtained for these two parameters are shown in Table 2. The values clearly shows that the present model is appropriate for these type of tight curvature.

Table 2 Performance indicators for the LFM test

\begin{tabular}{|c|c|c|}
\multicolumn{3}{|c|}{ case } \\
\hline Position & IA & NSE \\
\hline Section 8 & 0.995 & 0.980 \\
\hline Section 10 & 0.954 & 0.796 \\
\hline Section 12 & 0.980 & 0.916 \\
\hline Section 14 & 0.951 & 0.798 \\
\hline Section 16 & 0.963 & 0.845 \\
\hline Section 18 & 0.961 & 0.853 \\
\hline
\end{tabular}

\subsection{DHL Test Case}

Struiksma (1983) also considered uniform sediments with standard deviation of $\sigma_{\mathrm{g}}=1.19$ and specific gravity of 2.65 in his experiment. Two straight channel reaches of length $15 \mathrm{~m}$ each are also considered in the numerical simulation. The Mannings coefficient is calculated as 0.0237 . The Courant number value is 0.94 . The grid spacings considered in the straight portions are $\Delta \mathrm{x}=0.5236 \mathrm{~m}$ and $\Delta y=0.1875 \mathrm{~m}$. While in the bend portion these values are $\Delta \mathrm{r}=0.1875 \mathrm{~m}$ and $\Delta \varphi=2.50$. This has leads to 1035 grids for the whole flow domain. The sediment shape factor is considered as 2 . The upstream discharge is 0.061 cumec and the downstream water depth is $0.1 \mathrm{~m}$. The bed elevation is kept as constant at both the upstream and downstream boundaries. Starting from the initial bed the model is run upto steady state by considering time as the iteration parameter.

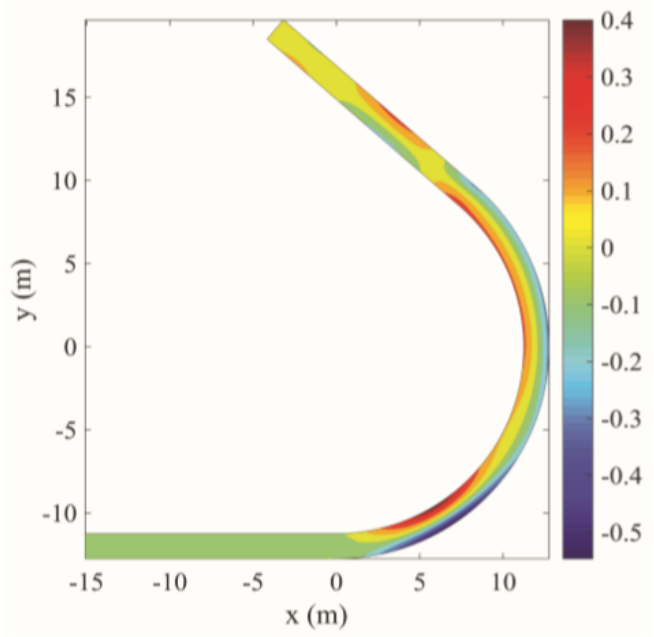

Fig. 5. Computed relative bed variations with respect to initial water depth $\left(\Delta \mathrm{Z} / \mathrm{H}_{0}\right)$ for $\mathrm{DHL}$ test case.

Figure 5 shows the relative bed change on imensionalized with initial water depth $\left(\Delta \mathrm{Z} / \mathrm{H}_{0}\right)$. This figure clearly shows the bigger pool on the outer bank and the point bar on the inner bank, downstream of the bend entrance. The model can also replicate the smaller pool and the point bar around 


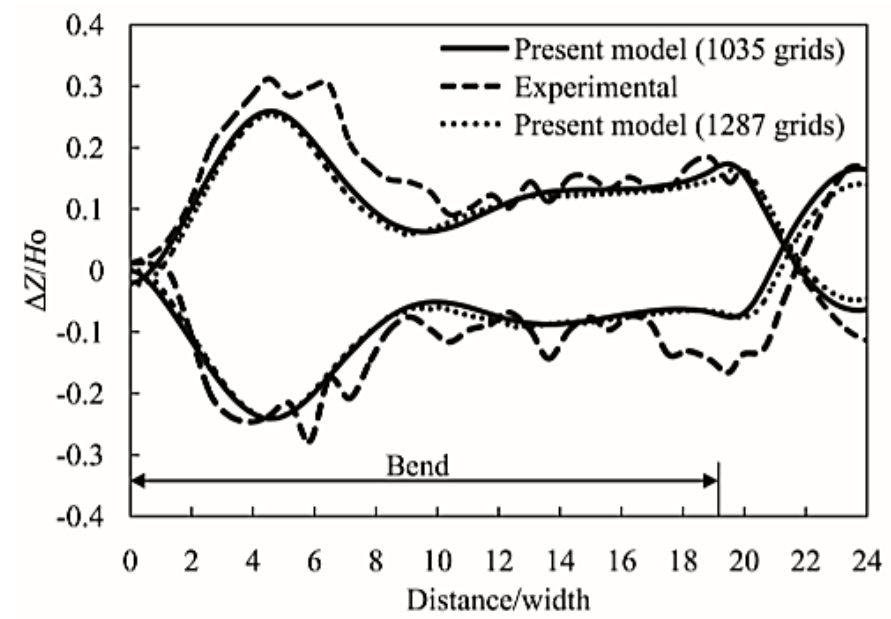

Fig. 6. Comparison of bed level variations along two longitudinal sections for DHL test case.

the exit of the bend. Moreover, the alternate bars on the downstream of the bend as observed in the experiment are exactly reproduced by the present model. For further analysis, numerical bed level variations along two longitudinal sections are also compared with the experimental results and are shown in Fig. 6. Figure 6 clearly shows that the present model compares satisfactorily with the experimental result. The point bar and the pool near the entrance of the bend are clearly reproduced. However, there is some discrepancy between the experimental and the numerical results for the pool around the exit of the bend. This discrepancy was also observed by Kassem and Chaudhry (2002). Kassem and Chaudhry (2002) claimed that it may be due to the uncertainties in the sediment discharge calculation and evaluation of sediment movement direction. The statistical parameter Brier Skill Score (BSS) (Davis 1984; Guan, Wright, Sleigh, Ahilan, and Lamb 2016) is used here for quantitative analysis of the numerical results. The BSS parameter is given by

$B S S=1-\frac{\sum_{i=1}^{n n}\left(z_{n u m}(t)-z_{\text {exp }}(t)\right)^{2}}{\sum_{i=1}^{n n}\left(z_{\text {num }}(t)-\overline{z_{\text {exp }}}(0)\right)^{2}}$

The BSS values are found to be 0.93 and 0.83 for the inner bank and the outer bank, respectively and are well within the excellent range (Guan, Wright, Sleigh, Ahilan, and Lamb 2016). In order to check the effect of grid size on the computed results, another grid is also considered. For this case the total number of grids is 1287 . The numerical results for this grid size is also shown in Fig. 6. The results clearly show that both the grids are showing almost similar results. Therefore, it may be concluded that with further decrease in grid size will not provide any remarkable change in the results.

\section{CONCLUSION}

This study presents a 2D depth averaged unsteady numerical model for morphological flow simulation in river bend. For this purpose, a hydrodynamic model and a sediment transport model are coupled with the efficient semicoupled approach. The hydrodynamic model solves the shallow water equations in a boundary fitted coordinate system to make the model compatible with river bends. A simple but efficient TVD MacCormack scheme is used here for solution of the governing hydrodynamic equations. The sediment transport model is developed by solving the Exner equation in a boundary fitted coordinate system. The simple FTCS scheme is used for discretization of the governing sediment transport equation. The sediment transport model incorporates the secondary flow effects by a pseudo 3D model. The effects of transverse bed slope on the sediment transport direction are included by a simple bed slope correction formula.

To verify the applicability of present model it is applied to replicate the bed level variations in two experimental channel bends. These experimental test cases include both tight and loose bends to affirm the potential of the model in diverse situations. The results show that the model can excellently simulate the point bars near the inner bank and the pools near the outer bank in the bend. The alternate bar formations downstream of the bend are also replicated accurately. Three popular statistical parameters are calculated for quantitative analysis of the results and the values obtained establish the potential of the present model for this type of complex river phenomenon.

The present model assumes uniform sediment in the river and therefore cannot include the grain sorting as well as armoring effects of bed sediment. This may be a future work of the present model. The effect of suspended sediment on the bed level variation can also be included in the model and is considered as the future scope of the present work. Another scope of future work may be use of some advanced and complex turbulence models. 


\section{ACKNOWLEDGMENTS}

The second author gratefully acknowledges the Department of Science and Technology, India (DST No: ECR/2016/000541) for the grant.

\section{REFERENCES}

Abad, J. D., G. C. Buscaglia and M. H. Garcia (2008). 2d stream hydrodynamic, sediment transport and bed morphology model for engineering applications. Hydrological Processes: An International Journal 22(10), 1443-1459.

Abad, J. D. and M. H. Garcia (2009). Experiments in a high-amplitude kinoshita meandering channel: 2. implications of bend orientation on bed morphodynamics. Water Resources Research 45 W02401.

Alauddin, M. and T. Tsujimoto (2012). Optimum configuration of groynes for stabilization of alluvial rivers with fine sediments. International Journal of Sediment Research 27(2), 158-167.

Anderson, D., J. C. Tannehill and R. H. Pletcher (1984). Computational fluid mechanics and heat transfer. CRC Press.

Begnudelli, L., A. Valiani and B. F. Sanders (2010). A balanced treatment of secondary currents, turbulence and dispersion in a depth-integrated hydrodynamic and bed de-formation model for channel bends. Advances in Water Resources 33(1), 17-33.

Bellos, V., I. Kourtis, A. Moreno-Rodenas and V. Tsihrintzis (2017). Quantifying rough-ness coefficient uncertainty in urban flooding simulations through a simplified methodology. Water 9(12), 944.

Bellos, V. and G. Tsakiris (2015). Comparing various methods of building representation for $2 \mathrm{~d}$ flood modelling in built-up areas. Water Resources Management 29(2), 379-397.

Chaudhry, M. H. (2007). Open-channel flow. Springer Science \& Business Media.

Davis, S. F. (1984). Tvd finite difference schemes and artificial viscosity.

Demuren, A. (1991). Development of a mathematical model for sediment transport in meandering rivers. Institut für Hydromechanik an der Universität Karlsruhe.

El-Khudairy, M. (1970). Stable bed profiles in continuous bends.

Elder, J. (1959). The dispersion of marked fluid in turbulent shear flow. Journal of fluid mechanics 5(4), 544-560.

Engelund, F. (1974). Flow and bed topographyin channel bends. Journal of the Hydraulics Division 100(Proc. Paper 10963).
Flokstra, C. and F. Koch (1981). Numerical aspects of bed level predictions for alluvial river bends. Delft Hydraulics Laboratory. Netherlands, Publication (258).

Garcia, M. and Y. Ni ñ o (1993). Dynamics of sediment bars in straight and meandering channels: experiments on the resonance phenomenon. Journal of Hydraulic Research 31(6), 739-761.

Guan, M., N. Wright, P. Sleigh, S. Ahilan and R. Lamb (2016). Physical complexity to model morphological changes at a natural channel bend. Water Resources Research 52(8), 63486364.

Hooke, R. L. (1974). Shear-stress and sedimentdistribution in a meander bend. Department of Physical Geography UNGI Rapport 30.

Kassem, A. A. and M. H. Chaudhry (2002). Numerical modeling of bed evolution in channel bends. Journal of Hydraulic Engineering 128(5), 507-514.

Khosronejad, A., J. Kozarek, P. Diplas, C. Hill, R. Jha, P. Chatanantavet, N. Heydari and F. Sotiropoulos (2018). Simulation-based optimization of in-stream structures design: rock vanes. Environmental Fluid Mechanics 18(3), 695-738.

Khosronejad, A., J. L. Kozarek, M. L. Palmsten and F. Sotiropoulos (2015). Numerical simulation of large dunes in meandering streams and rivers with in-stream rock structures. Advances in water resources $81,45-61$.

Khosronejad, A., C. Rennie, S. Salehi Neyshabouri and R. Townsend (2007). 3d numerical modeling of flow and sediment transport in laboratory channel bends. Journal of hydraulic Engineering 133(10), 1123-1134.

Kikkawa, H., S. Ikeda and A. Kitagawa (1976). Flow and bed topography in curved open channels. Journal of the Hydraulics Division 102 (ASCE\# 12416).

Lane, S. and R. Ferguson (2005). Modelling reachscale fluvial flows. Computational Fluid Dynamics, 215-269.

Lee, S. and T. Dang (2018). Experimental investigation and numerical simulation of morphological changes in natural channel bend. Journal of Applied Fluid Mechanics 11(3).

Liang, D., B. Lin and R. A. Falconer (2007). A boundary-fitted numerical model for flood routing with shock-capturing capability. Journal of hydrology 332(3-4), 477-486.

Liang, D., I. Özgen, R. Hinkelmann, Y. Xiao and J. M. Chen (2015). Shallow water simulation of overland flows in idealised catchments. Environmental Earth Sciences 74(11), 73077318. 
MacCormack, R. (2003). The effect of viscosity in hypervelocity impact cratering. Journal of spacecraft and rockets 40(5), 757-763.

Nash, J. E. and J. V. Sutcliffe (1970). River flow forecasting through conceptual models partia discussion of principles. Journal of hydrology 10(3), 282-290.

Odgaard, A. J. (1981). Transverse bed slope inalluvial channel bends. Journal of the Hydraulics Division 107(12), 1677-1694.

Olesen, K. W. (1985). A mathematical model of the flow and bed topography in curved channels. Communications on hydraulics, 1985- 01.

Parker, G., K. Sawai and S. Ikeda (1982). Bend theory of river meanders. part 2. nonlinear deformation of finite-amplitude bends. Journal of Fluid Mechanics 115, 303-314.

Rahman, M., N. Nagata, T. Hosoda and Y. Muramoto (1996). Experimental study on morphological process of meandering channels with bank erosion. Proceedings of HyDraulic Engineering 40, 947-952.

Ramamurthy, A., S. Han and P. Biron (2012). Threedimensional simulation parameters for 90 open channel bend flows. Journal of Computing in Civil Engineering 27(3), 282-291.

Roca, M., J. P. Martín-Vide and K. Blanck-aert (2007). Reduction of bend scour by an outer bank footing: Footing design and bed topography. Journal of Hydraulic Engineering 133(2), 139-147.

Seminara, G., G. Zolezzi, M. Tubino and D. Zardi (2001). Downstream and upstream influence in river meandering. part 2 . planimetric development. Journal of Fluid Mechanics 438, 213-230.

Shimizu, Y. and T. Itakura (1989). Calculation of bed variation in alluvial channels. Journal of Hydraulic Engineering 115(3), 367-384.

Soulis, J. V. (2002). A fully coupled numerical technique for $2 \mathrm{~d}$ bed morphology calculations. International journal for numerical methods in fluids 38(1), 71-98.

Strang, G. (1968). On the construction and comparison of difference schemes. SIAM journal on numerical analysis 5(3), 506-517.

Struiksma, N. (1983). Results of movable bed experiments in the dhl curved flume. Report on Experimental Investigation, TWO Rep. No. R657-XVIII M 1771.

Struiksma, N., K. Olesen, C. Flokstra and H. De Vriend (1985). Bed deformation in curved alluvial channels. Journal of Hydraulic Research 23(1), 57-79.

Sutmuller, A. and H. Glerum (1980). Description and evaluation of measurements carried out in a bend flume with sand bed. Delft University of Technology, Department of Civil Engineering, Report (14710101).

Tsakiris, G. and V. Bellos (2014). A numerical model for two-dimensional flood routing in complex terrains. Water resources management 28(5), 1277-1291.

Uddin, M. N. and M. M. Rahman (2012). Flow and erosion at a bend in the braided jamuna river. International Journal of Sediment Research 27(4), 498-509.

Vasquez, J. A. (2005). Two dimensional finite element river morphology model. $\mathrm{Ph}$. D. thesis, The University of British Columbia, Canada.

Vasquez, J. A., P. M. Steffler and R. G. Millar (2008). Modeling bed changes in meandering rivers using triangular finite elements. Journal of Hydraulic Engineering 134(9), 1348-1352.

Wang, S. and S. Adeff (1986). Three-dimensional modeling of river sedimentation processes. In Proc. of the 3rd Int. Symp. on River Sedimentation.

Willmott, C. J. (1981). On the validation of models. Physical geography 2(2), 184-194.

Wu, W. (2007). Computational river dynamics. CRC Press.

Wu, W., W. Rodi and T. Wenka (2000). 3d numerical modeling of flow and sediment transport in open channels. Journal of hydraulic engineering 126(1), 4-15.

Zimmerman, C. and J. F. Kennedy (1978). Transverse bed slopes in curved alluvial streams. Journal of the Hydraulics Division 104(ASCE 13482 Proceeding). 